\title{
ARSENICO EM NERVOS PERIFÉRICOS NORMAIS DO HOMEM
}

\author{
Abrão ANGHinah * \\ Francisco B. DE JORGE ** \\ Francisco Forti *** \\ ANTONIO F. FERRARI ****
}

A inclusão do arsênico inorgânico entre os constituintes normais do organismo humano foi durante muitos anos motivo de controvérsias entre vários toxicologistas. A opinião da maioria dos pesquisadores foi sintetizada por Kunkel em 1899 (cit. Ecker e Kernohan ${ }^{2}$ ), que considerava sem valor significativo (milésimos de miligramas em um dado órgão) a quantidade de arsênico habitualmente encontrada nos vários tecidos do organismo humano normal.

As referências bibliográficas (Alexander e Myerson ${ }^{1}$, McIlwain ${ }^{5}$, Lowenthal ${ }^{4}$ ), salvo alguma omissão de nossa parte, dizem respeito a dosagens realizadas na urina, cabelos, unhas, derma e cérebro, nada constando a propósito de pesquisas realizadas em nervos periféricos do homem.

O presente trabalho constitui uma contribuição para o conhecimento do conteúdo de arsênico inorgânico nos nervos cubtial e tibial anterior de indivíduos sem afeç̧ões neurológicas. Acreditamos que tal estudo servirá de base para a interpretação de dados relacionados com o conteúdo deste elemento em nervos periféricos de pacientes com polineuropatia arsenical.

\section{MATERIAL E MÉTODOS}

Durante a realização de necropsias, foram excisados fragmentos de nervos periféricos (10 de nervo cubital e 10 de nervo tibial anterior) em 20 cadáveres, antes de decorridas 24 horas após o óbito. Destes, 13 pertenciam ao sexo masculino e 7 ao sexo feminino, com idades variando entre 19 e 68 anos.

As causas determinantes do óbito foram as seguintes: em 6, politraumatismos; em 4, traumatismos cranianos; em 2, hemorragia interna pós-traumática; em 2, enfarte do miocárdio; em 2, afogamento; em 1, intoxicação por gás de rua e, em 1, asfixia pós-enforcamento.

Trabalho realizado na Clinica Neurológica (Prof. H. M. Canelas) do Hospital das Clínicas da Faculdade de Medicina da Universidade de São Paulo: * Assistente; ** Chefe de Laboratório da Fac. Med. Mogi das Cruzes; *** Residente.

Nota dos autores - Os autores agradecem ao Dr. Arnaldo Siqueira, Diretor do Instituto Médico-Legal de São Paulo, a permissão para retirada de fragmentos de nervos durante a necropsia dos casos incluídos neste estudo. 
Os espécimes foram secados a $105^{\circ} \mathrm{C}$ em estufa até se conseguir peso constante. Os tecidos secos foram incinerados em forno-mufla regulado potenciometricamente a 5500 durante aproximadamente 12 horas (durante a noite). Para a determinação do arsênico inorgânico preparou-se solução das cinzas com ácido clorídrico concentrado. As quantidades de arsênico foram determinadas pelo método de KingsleySchaffert ${ }^{3}$.

R E S U T A D OS

O método empregado demonstrou que, em 20 espécimes de nervos periféricos aparentemente normais ( 10 de nervo cubital e 10 de nervo tibial anterior), foram encontrados traços indosáveis (sem valor significativo) de arsênico inorgânico.

\section{S U M M A R Y}

Inorganic arsenic in normal human peripheral nerves.

As a contribution to the knowledge on inorganic arsenic concentration in peripheral nerves, a study was carried out in 20 nerve fragments (10 from $n$. ulnaris and 10 from $n$. tibialis) excised during necropsy from 20 corpses less than 24 hours after death and showing no apparent disease of the nervous system. The samples were ashed in an oven overnight at $550^{\circ} \mathrm{C}$. The ashes were dissolved in a known volume of $2 \mathrm{~N}-\mathrm{HCl}$. In this solution inorganic arsenic was determined by the Kingsley-Schaffert method. The results revealed no significant concentrations (vestiges) of inorganic arsenic in the peripheral nerves.

\section{R EFERENCIA S}

1. ALEXANDRE, L. \& MYERSON, A. - Minerals in normal and in pathologic brain tissue, studied by micro-incineration and spectroscopy. Arch. Neurol. Psychiat. (Chicago) 39:131, 1938.

2. ECKER, A. D. \& KERNOHAN, S. W. - Arsenic as a possible cause of subacute encephalomyelitis. Arch. Neurol. Psychiat. (Chicago) 45:24, 1945.

3. KINGSLEY, G. R. \& SCHAFFERT, R. R. - Microdetermination of arsenic and its application to biological material. Anal. Chem. 23:914, 1951.

4. LOWENTHAL, A. - The metals of the human system. In Tedeschi, C. G. - Neuropathology, Methods and Diagnosis. Little-Brown, Boston, 1970, pp. 769-778.

5. McIlWAIN, H. - Biochemistry and Central Nervous System. Churchill, London, ed. 3,1966, p. 28.

Clínica Neurológica - Hospital das Clínicas - Faculdade de Medicina - Caixa Postal 3461 - 01000 São Paulo, SP — Brasil. 